\title{
Characteristics of Rathke's cleft cyst based on cyst location with a primary focus on recurrence after resection
}

\author{
*Silky Chotai, MD, Yi Liu, MD, PhD, Jun Pan, MD, PhD, and Songtao Qi, MD, PhD \\ Department of Neurosurgery, Nanfang Hospital, Southern Medical University, Guangzhou, Guangdong, People's Republic of China
}

OBJECT Rathke's cleft cysts (RCCs) are benign lesions with a location that is entirely intrasellar, intrasellar with suprasellar extension (intrasuprasellar), or purely suprasellar. The recurrence of RCC is relatively uncommon. The present study was conducted to report clinical characteristics, histological features, and outcomes based on location of the cyst with a primary focus on analyzing the predictors of squamous metaplasia and recurrence in these 3 types of RCCs.

METHODS A retrospective review of the medical records of patients with symptomatic RCCs who had undergone resection at the authors' institution was conducted. Data points, including clinical presentation, preoperative endocrine status, operative details, imaging findings, pathology, and clinical outcomes, were reviewed. A multivariable regression model was used to identify predictors of recurrence.

RESULTS The mean age of the 87 eligible patients, 64 females and 23 males, was $41 \pm 14$ years (range 10-73 years). Sixteen patients (18\%) had an entirely intrasellar RCC, $21(24 \%)$ had a purely suprasellar cyst, and $50(58 \%)$ had an intrasuprasellar RCC. The mean cyst volume was $2.4 \pm 0.9 \mathrm{~cm}^{3}$ (range $\left.0.36-4.9 \mathrm{~cm}^{3}\right)$. Headache was the most frequent initial symptom (76\%) followed by visual disturbance $(45 \%)$. The transsphenoidal approach was performed for all intrasellar RCCs (16 cysts) and 33 of 50 intrasuprasellar RCCs. The transcranial route was used for all suprasellar cysts (21 cysts) and 17 of 50 intrasuprasellar RCCs. Squamous metaplasia was present in $27(31 \%)$ of 87 RCCs. The occurrence of squamous metaplasia was associated with cyst location $(p=0.027)$, T1 signal intensity $(p=0.004)$ and ring enhancement on Gd-enhanced MRI $(p=0.017)$, and cyst volume ( $p=0.045)$. A suprasellar location $(p=0.048,0 R 3.89,95 \%$ $\mathrm{Cl} 1.010-15.020)$, ring enhancement on Gd-enhanced MRI ( $p=0.028$, OR 3.922, 95\% Cl 1.158-13.288), hypointensity on T1-weighted MRI ( $p=0.002$, OR $6.86,95 \% \mathrm{Cl} 1.972-23.909)$, and cyst volume $(p=0.01, \mathrm{OR} 0.367,95 \% \mathrm{Cl} 0.170$ 0.789 ) were independent predictors of squamous metaplasia. The mean time to reaccumulation (11 [12.6\%] of 87 cases) and recurrence $(7[8 \%]$ of 87 cases) was $14 \pm 6$ months. Recurrence-free survival was $84.5 \%$ at a mean of $98.2 \pm 4.6$ months after treatment. A suprasellar cyst location ( $p=0.007$, OR 7.7, $95 \% \mathrm{Cl} 1.75-34.54)$, the occurrence of squamous metaplasia ( $p=0.007$, OR 19.3, 95\% Cl 2.25-165.18), and isointensity on T2-weighted MRI ( $p=0.041,0 R 10.29,95 \%$ $\mathrm{Cl} 1.094-96.872$ ) were the independent predictors of RCC recurrence.

CONCLUSIONS A suprasellar cyst location, the occurrence of squamous metaplasia, and isointensity on T2-weighted MRI were independent predictors of RCC recurrence. The extent of resection and type of surgical approach used were not associated with recurrence. A tailored extent of resection based on cyst location and predictive factors is recommended.

http://thejns.org/doi/abs/10.3171/2014.12.JNS14596

KEY WORDS Rathke's cleft cyst; RCC; intrasellar; suprasellar; recurrence; squamous metaplasia; resection; oncology

$\mathrm{R}$ ATHKE's cleft cysts (RCCs) are nonneoplastic epithelial lesions of the sellar and suprasellar region. They are typically asymptomatic with a slow growth rate. An asymptomatic RCC is most often diagnosed at autopsy with a reported incidence of 5\%-33\%.5,47-49 Quite often some RCCs grow over time and can become suffi- ciently large to cause a compressive effect on surrounding structures, resulting in neurological and endocrine abnormalities. $7,28,37,42$ A symptomatic RCC was first described by Goldzieher ${ }^{17}$ in 1913, and this type of cyst follows a variable natural history. Some cysts undergo spontaneous resolution, ${ }^{2}$ and others have reductions in cyst size and

\footnotetext{
ABBREVIATIONS DI = diabetes insipidus; $R C C=$ Rathke's cleft cyst; RFS = recurrence-free survival. SUBMITTED March 15, 2014. ACCEPTED December 18, 2014. INCLUDE WHEN CITING Published online February 13, 2015; DOI: 10.3171/2014.12.JNS14596.

DISCLOSURE The authors report no conflict of interest concerning the materials or methods used in this study or the findings specified in this paper. This study was supported by grants from the Natural Science Foundation of Guang Dong province (Grant No. 2011010003063 and Grant No. 2011020005179) and from the National Natural Science Foundation of China (Grant No. 81072067).

* Drs. Chotai and Liu contributed equally to this work.
} 
symptoms after treatment with glucocorticoids ${ }^{32}$ Most often the surgically treated RCC remains stable during the long-term follow-up; however, a good number of RCCs are prone to recurrence. Numerous authors have reported their experience in the management of RCCs and have speculated about an association between recurrence and various clinical or histopathological features. $6,18,30,33,34,39$ Nonetheless, the factors that predict recurrence after surgical treatment are still debatable. ${ }^{38,54}$

Rathke's cleft cysts are believed to be derived from true remnants of the embryological Rathke's pouch. ${ }^{3,11,16,23}$ As regards the development of RCC, theoretically, during the 3 rd or 4th week of gestation, a rostral outpouching of the ectodermal primitive oral cavity meets a downward projection from the neuroectodermal diencephalon. These structures then give rise to the anterior lobe, pars tuberalis, and pars intermedia of the pituitary gland., ${ }^{3,19,44}$ The residual lumen between the anterior and intermediate lobe constitutes Rathke's cleft. The remnant of Rathke's cleft between the anterior lobe and the pars intermedia can result in an accumulation of fluid and cystic dilation leading to the purely intrasellar RCC or an intrasellar RCC with suprasellar (intrasuprasellar) extension. ${ }^{44,51}$ The pars tuberalis lies above the diaphragm, and the Rathke's pouch remnants in this location can give rise to an entirely suprasellar RCC. ${ }^{4}$ Entirely suprasellar RCCs with a normal sella turcica are relatively rare (incidence 0\%-20\%). ${ }^{8,12,13,15,20,24,25,31,36,39} \mathrm{Su}-$ prasellar, intrasuprasellar, and intrasellar RCCs are distinct entities with respect to their clinical presentation, resectability, postoperative recurrence, and outcomes. Few authors have classified RCCs based on cyst location and have compared the presentations, different surgical approaches, pathological types, and surgical outcomes. ${ }^{39}$ The present study was conducted to report clinical characteristics, histological features, and outcomes of surgically treated symptomatic RCCs. Our primary focus was to analyze the predictors of squamous metaplasia and recurrence in the 3 types of RCCs classified based on cyst location.

\section{Methods}

A retrospective review of the medical records for all patients with symptomatic RCCs who had undergone resection at our institution between January 2002 and January 2012 was conducted after obtaining approval from our local ethics committee. Data points, including clinical presentation, preoperative endocrine status, operative details, imaging findings, pathology reports, and clinical outcomes, were reviewed. Preoperative pituitary function was evaluated through laboratory assessment of adrenocorticotropic hormone, growth hormone, insulin-like growth factor, prolactin levels, thyroid-stimulating hormone, thyroxin, follicle-stimulating hormone, luteinizing hormone, testosterone, and morning cortisol levels. The precise cyst location, size (calculated using the Coniglobus formula), and cyst characteristics were evaluated on Gd-enhanced T1-weighted MRI. The variation in signal intensity of the cyst on T1- and T2-weighted MRI was noted.

\section{Surgical Removal}

Resection is performed in all symptomatic patients with laboratory evidence of hypopituitarism, documented growth of the lesion on serial imaging, and an uncertain or alternative preoperative diagnosis. Selection of the surgical approach is based on the location of the cyst on preoperative MRI. Transsphenoidal or subfrontal, frontotemporal, and supraorbital approaches with endoscopic assistance or pure endoscopic technique were used in this study. The details of these approaches have been described in our previous publication. ${ }^{13}$ The essential principle during resection of an RCC is to avoid manipulation of the normal pituitary gland to minimize the risk of gland injury. Complete excision of the cyst wall is attempted whenever possible. Radical resection of the cyst wall with the intention of reducing the recurrence rate was performed in 15 cases treated early in the series. For later cases in the series, the cyst contents were totally removed, and the cyst wall was partially resected to avoid transgression of surrounding structures. For cases in which no defect in the suprasellar arachnoid is identified, hydrogen peroxide is placed in the cyst cavity for 2 minutes after complete removal of the cyst contents with the intention of decimating the cyst wall lining and theoretically decreasing the proliferative ability of any residual cyst wall. The extent of resection of the cyst wall was identified based on video recordings of the surgical procedure and postoperative imaging. Specimens obtained at surgery are fixed in 10\% formalin and cut into sections, and the tissues are stained with $\mathrm{H} \& \mathrm{E}$. The histopathological slides are re-reviewed by a pathologist, and the cysts are classified as having or not having squamous metaplasia. An immediate postoperative MRI study is obtained within 48 hours of surgery to evaluate the extent of removal.

\section{Follow-Up}

Follow-up is scheduled at 3 and 9 months after surgery and annually thereafter. Magnetic resonance imaging is performed at each follow-up visit. Pituitary function is monitored by hormone level assessment at 1, 3, 6, and 12 months after surgery. Recurrence was defined as the reaccumulation of cyst contents on follow-up imaging with or without symptomatic recurrence.

\section{Statistical Analysis}

The mean \pm standard deviation, median, and range for continuous variables and the frequency for discrete data were calculated for patient demographics. Univariate analysis using the chi-square test for categorical variables and the Mann-Whitney U-test or Kruskal-Wallis test for continuous variables was performed to evaluate the association of clinical parameters with the location of the RCC, the occurrence of squamous metaplasia, and recurrence. Multivariable binary logistic regression analysis was conducted to evaluate the predictors of squamous metaplasia. The Hosmer-Lemeshow statistic was used to assess the fit of the models. Kaplan-Meier analyses with the log-rank model were used to evaluate recurrence-free survival (RFS). Multivariable stepwise Cox proportional-hazards regression analysis was used to identify independent predictors of recurrence. All variables with a $\mathrm{p}$ value $\leq 0.05$ in the univariate analysis, in addition to age at the time of 
surgery and histology, were included as independent variables. All the analyses were tested at the 0.05 level of significance, and the analysis was performed using the SPSS version 20 (IBM Inc.).

\section{Results}

The mean age of the 87 patients eligible for this study was $41 \pm 14$ years (range 10-73 years). There were 64 female (74\%) and 23 male (26\%) patients. Among the entire population, 16 patients $(18 \%)$ had an entirely intrasellar RCC (Fig. 1), 50 (58\%) had an intrasuprasellar cyst (Fig. 2), and 21 (24\%) had a purely suprasellar lesion (Fig. 3 and Table 1). The mean cyst volume was $2.4 \pm 0.9 \mathrm{~cm}^{3}$ (range $\left.0.36-4.9 \mathrm{~cm}^{3}\right)$.

\section{Preoperative Findings}

Headache was the most frequent initial symptom, occurring in 66 cases (76\%). Visual disturbance was reported in 39 patients (45\%). Preoperative hyperprolactinemia, hypopituitarism, and diabetes insipidus (DI) were found in $31(36 \%), 29(33 \%)$, and 17 (20\%) patients, respectively. Thirty-one patients had more than 1 of these presenting symptoms. The incidence of preoperative symptoms was not significantly associated with recurrence. The incidence of hyperprolactinemia was significantly higher in patients with the intrasellar type of cyst $(\mathrm{p}=0.005)$. In 29 patients with hypopituitarism, hypocortisolism was the most common dysfunction (24\%), followed by hypothyroidism (20\%), hypogonadism (15\%), and growth hormone deficiency $(10 \%)$. Fourteen patients had hormonal deficiency in 2 or more hormonal axes. The mean duration of preoperative symptoms was $17 \pm 23$ months (range 1-108 months). The RCCs demonstrated variable signal intensity on T1- and T2-weighted MRI (Tables 1 and 2).

\section{Surgical Details}

The transsphenoidal approach was used for all intrasellar RCCs (16 cases) and the intrasuprasellar RCCs with only a thin portion of or no pituitary gland occupying the sellar floor (33 cases; Table 1). The transcranial route was used to access purely suprasellar cysts (21 cases) and intrasuprasellar cysts with gland covering a major part or most of the sellar floor (17 cases). Traditional craniotomies were performed in 18 cases treated between 2002 and
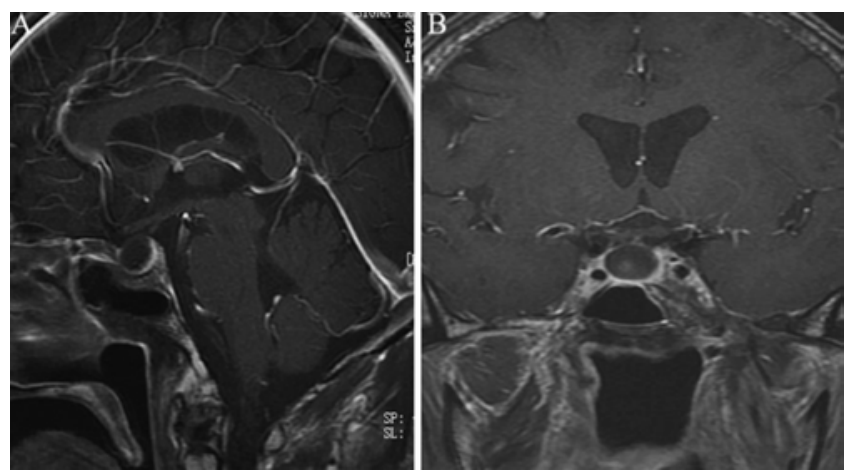

FIG. 1. Sagittal (A) and coronal (B) T1-weighted Gd-enhanced MR images showing an entirely intrasellar RCC.
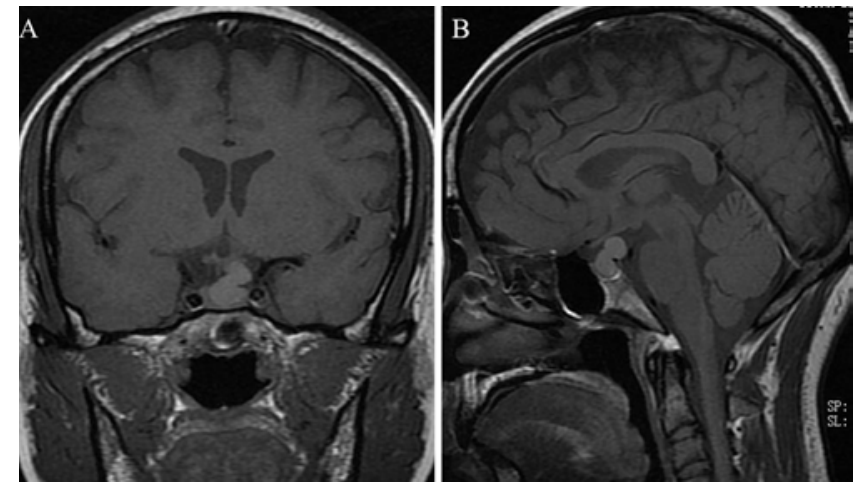

FIG. 2. Coronal (A) and sagittal (B) T1-weighted MR images showing an intrasellar RCC with suprasellar extension (intrasupracellar).

2006. Since 2006, a supraorbital keyhole approach was used (17 cases); traditional craniotomies were only used for 3 lesions with an uncertain preoperative diagnosis or in those cases in which the residual pituitary gland was displaced inferiorly, which could block the trajectory via the endonasal approach. ${ }^{13}$ Fifteen patients had complete excision of the cyst wall; 6 patients (40\%) developed new hypopituitarism postoperatively. Complications resulting from surgery included CSF leakage, infection, new-onset hypopituitarism, and DI (Table 1). Postoperative CSF leakage occurred in $3.4 \%$ of patients ( 3 of 87 ), all of whom had undergone endonasal surgery; the leak resolved with bed rest and/or lumbar drainage in all of the patients. Five patients $(6 \%)$ experienced new DI, whether temporary or permanent; there was no significant difference in the occurrence of DI among the 3 cyst groups $(p=0.47)$. Permanent DI occurred in only 1 patient. The postoperative infection rate (8 [9\%] of 87 patients) was associated with squamous metaplasia $(\mathrm{p}=0.04)$.

\section{Squamous Metaplasia}

Squamous metaplasia was present in $27(31 \%)$ of 87 RCCs: 2 (13\%), 14 (28\%), and 11 (52\%) cases were intrasellar, intrasuprasellar, and suprasellar, respectively (Table 1). The occurrence of squamous metaplasia was associated with cyst location $(\mathrm{p}=0.027), \mathrm{T} 1$ signal intensity ( $\mathrm{p}$ $=0.004)$ and ring enhancement on Gd-enhanced MRI $(\mathrm{p}=0.017)$, and cyst volume $(\mathrm{p}=0.045)$. In multivariable logistic regression analysis, a suprasellar location ( $p$
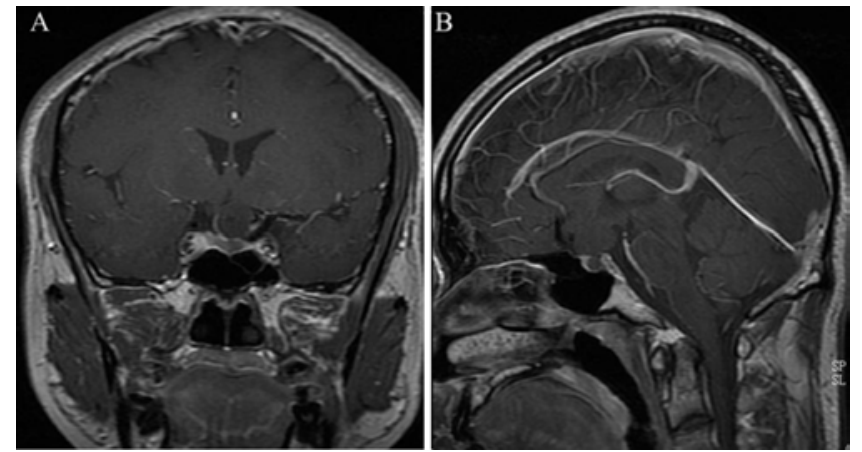

FIG. 3. Coronal (A) and sagittal (B) Gd-enhanced T1-weighted MR images showing an entirely suprasellar RCC. 
TABLE 1. Clinical characteristics of patients with RCCs, based on cyst location

\begin{tabular}{|c|c|c|c|c|c|}
\hline \multirow[b]{2}{*}{ Characteristic } & \multicolumn{4}{|c|}{ No. (\%) } & \multirow[b]{2}{*}{ p Value } \\
\hline & Overall & Intrasellar & Intrasuprasellar & Suprasellar & \\
\hline Age in yrs & $41 \pm 14$ & $43 \pm 11$ & $42 \pm 14$ & $35 \pm 13$ & 0.08 \\
\hline \multicolumn{6}{|l|}{ Sex } \\
\hline Female & $64(74)$ & 8 & 42 & 14 & $0.019^{*}$ \\
\hline Male & $23(26)$ & 8 & 8 & 7 & \\
\hline \multicolumn{6}{|l|}{ Preop symptom } \\
\hline Headache & $66(76)$ & 12 & 36 & 18 & 0.466 \\
\hline Visual disturbance & $39(45)$ & 4 & 22 & 13 & 0.08 \\
\hline DI & $17(20)$ & 3 & 8 & 6 & 0.474 \\
\hline Hypopituitarism & $29(33)$ & 7 & 15 & 7 & 0.597 \\
\hline Hyperprolactinemia & $31(36)$ & 12 & 11 & 8 & $0.005^{*}$ \\
\hline Mean duration of symptoms in mos & $17 \pm 23$ & $12 \pm 14$ & $21 \pm 28$ & $10 \pm 13$ & 0.124 \\
\hline \multicolumn{6}{|l|}{ Cyst vol in $\mathrm{cm}^{3}$} \\
\hline$<2.5$ & $23(27)$ & 5 & 8 & 10 & $<0.023^{*}$ \\
\hline $2.5-3.5$ & $36(41)$ & 9 & 21 & 6 & \\
\hline$>3.5$ & $28(32)$ & 2 & 21 & 5 & \\
\hline T1-weighted MRI & & & & & 0.167 \\
\hline Hypointense & $30(35)$ & 4 & 14 & 12 & \\
\hline Isointense & $49(56)$ & 10 & 31 & 8 & \\
\hline Hyperintense & $8(9)$ & 2 & 5 & 1 & \\
\hline T2-weighted MRI & & & & & 0.106 \\
\hline Hypointense & $15(17)$ & 5 & 10 & 0 & \\
\hline Isointense & $40(46)$ & 5 & 22 & 13 & \\
\hline Hyperintense & $32(37)$ & 6 & 18 & 8 & \\
\hline T1 ring enhancement & $45(52)$ & 8 & 22 & 15 & 0.107 \\
\hline Surgical approach & & & & & $<0.0001^{*}$ \\
\hline TS & $49(56)$ & 16 & 33 & 0 & \\
\hline $\mathrm{TC}$ & $21(24)$ & 0 & 10 & 11 & \\
\hline TC/supraorbital keyhole & $17(20)$ & 0 & 7 & 10 & \\
\hline \multicolumn{6}{|l|}{ Resection } \\
\hline GTR & $15(17)$ & 0 & 11 & 4 & 0.124 \\
\hline STR & $72(83)$ & 16 & 39 & 17 & \\
\hline \multicolumn{6}{|l|}{ Complication } \\
\hline CSF leakage & $3(3)$ & 2 & 1 & 0 & 0.08 \\
\hline Infection & $8(9)$ & 0 & 4 & 4 & 0.12 \\
\hline Hematoma & $3(3)$ & 0 & 2 & 1 & 0.61 \\
\hline New hypopituitarism & $8(9)$ & 2 & 5 & 1 & 0.7 \\
\hline New DI & $5(6)$ & 0 & 4 & 1 & 0.47 \\
\hline \multicolumn{6}{|l|}{ Postop improvement } \\
\hline Headache & $56(64)$ & 11 & 33 & 12 & $0.03^{*}$ \\
\hline Vision improvement & $37(43)$ & 4 & 21 & 12 & 0.461 \\
\hline Hypopituitarism & $16(18)$ & 6 & 8 & 2 & $0.02^{*}$ \\
\hline DI & $11(13)$ & 3 & 4 & 4 & 0.3 \\
\hline Hyperprolactinemia & $29(33)$ & 11 & 10 & 8 & 0.18 \\
\hline Squamous metaplasia & $27(31)$ & 2 & 14 & 11 & $0.003^{*}$ \\
\hline Recurrence & $11(13)$ & 0 & 5 & 6 & $0.024^{*}$ \\
\hline
\end{tabular}

GTR = gross-total resection; STR = subtotal resection; TC = transcranial; TS = transsphenoidal.

* Statistically significant. 
TABLE 2. Univariate analysis of factors associated with RCC recurrence

\begin{tabular}{|c|c|c|c|c|}
\hline \multirow[b]{3}{*}{ Characteristic } & \multicolumn{3}{|c|}{ No. $(\%)$} & \multirow[b]{3}{*}{$\mathrm{p}$ Value } \\
\hline & \multirow[b]{2}{*}{ Overall } & \multicolumn{2}{|c|}{ Recurrence } & \\
\hline & & Yes & No & \\
\hline Mean age in yrs & $41 \pm 14$ & & & \\
\hline Age in yrs & & & & 0.05 \\
\hline$<18$ & $4(5)$ & 2 & 2 & \\
\hline $18-44$ & $45(52)$ & 7 & 38 & \\
\hline $45-60$ & $30(34)$ & 2 & 28 & \\
\hline$>60$ & $8(9)$ & 0 & 8 & \\
\hline \multicolumn{5}{|l|}{ Sex } \\
\hline Female & $64(74)$ & 6 & 18 & 0.126 \\
\hline Male & $23(26)$ & 5 & 58 & \\
\hline \multicolumn{5}{|l|}{ Preop symptom } \\
\hline Headache & $66(76)$ & 8 & 58 & 0.795 \\
\hline Visual disturbance & $39(45)$ & 7 & 32 & 0.180 \\
\hline DI & $17(20)$ & 2 & 15 & 0.903 \\
\hline Hypopituitarism & $29(33)$ & 4 & 25 & 0.820 \\
\hline Hyperprolactinemia & $31(36)$ & 2 & 29 & 0.196 \\
\hline Cyst type & & & & $0.024^{*}$ \\
\hline Intrasellar & $16(18)$ & 0 & 16 & \\
\hline Intrasuprasellar & $50(58)$ & 5 & 45 & \\
\hline Suprasellar & $21(24)$ & 6 & 15 & \\
\hline Cyst vol in $\mathrm{cm}^{3}$ & & & & 0.236 \\
\hline$<2.5$ & $23(27)$ & 2 & 21 & \\
\hline $2.5-3.5$ & $36(41)$ & 3 & 33 & \\
\hline$>3.5$ & $28(32)$ & 6 & 22 & \\
\hline T1-weighted MRI & & & & 0.703 \\
\hline Hypointense & $30(35)$ & 5 & 25 & \\
\hline Isointense & $49(56)$ & 5 & 44 & \\
\hline Hyperintense & $8(9)$ & 1 & 7 & \\
\hline \multicolumn{5}{|l|}{ T2-weighted MRI } \\
\hline Hypointense & $15(17)$ & 0 & 15 & \\
\hline Isointense & $40(46)$ & 10 & 30 & $0.006^{*}$ \\
\hline Hyperintense & $32(37)$ & 1 & 31 & \\
\hline T1-weighted Gd enhancement & $45(52)$ & 8 & 37 & 0.136 \\
\hline Surgical approach & & & & 0.749 \\
\hline TS & $49(56)$ & 6 & 43 & \\
\hline $\mathrm{TC}$ & $21(24)$ & 2 & 19 & \\
\hline TC/supraorbital & $17(20)$ & 3 & 14 & \\
\hline \multicolumn{5}{|l|}{ Resection } \\
\hline GTR & $15(17)$ & 2 & 13 & 0.930 \\
\hline STR & $72(83)$ & 9 & 63 & \\
\hline \multicolumn{5}{|l|}{ Complication } \\
\hline CSF leak & $3(3)$ & 0 & 3 & 0.502 \\
\hline Infection & $8(9)$ & 1 & 7 & 0.734 \\
\hline Hematoma & $3(3)$ & 0 & 3 & 0.663 \\
\hline New hypopituitarism & $8(9)$ & 2 & 6 & 0.266 \\
\hline New DI & $5(6)$ & 2 & 3 & 0.058 \\
\hline
\end{tabular}

TABLE 2. Univariate analysis of factors associated with RCC recurrence (continued)

\begin{tabular}{|c|c|c|c|c|}
\hline \multirow[b]{3}{*}{ Characteristic } & \multicolumn{3}{|c|}{ No. $(\%)$} & \multirow[b]{3}{*}{ p Value } \\
\hline & \multirow[b]{2}{*}{ Overall } & \multicolumn{2}{|c|}{ Recurrence } & \\
\hline & & Yes & No & \\
\hline \multicolumn{5}{|l|}{ Squamous metaplasia } \\
\hline Yes & $27(31)$ & 10 & 17 & $<0.0001^{*}$ \\
\hline No & $60(69)$ & 1 & 59 & \\
\hline
\end{tabular}

* Statistically significant.

$=0.048$, OR 3.89, 95\% CI 1.010-15.020), ring enhancement on Gd-enhanced MRI ( $\mathrm{p}=0.028$, OR 3.922, 95\% CI 1.158-13.288), hypointensity on T1-weighted MRI ( $\mathrm{p}=$ 0.002 , OR 6.86, 95\% CI 1.972-23.909), and cyst volume (p $=0.01$, OR $0.367,95 \%$ CI $0.170-0.789)$ were the independent predictors of squamous metaplasia.

\section{Follow-Up and Outcomes}

The mean duration of follow-up was $54 \pm 29$ months (median 60 months, range 9-131 months). Preoperative headaches improved in $56(85 \%)$ of 66 patients. There was a significant difference in the rate of postoperative headache improvement among the RCC types; the rate of improvement was highest in the intrasellar type (92\%) and lowest in the suprasellar (66\%; $\mathrm{p}=0.03)$. Of the $39 \mathrm{pa}-$ tients presenting with visual dysfunction, 37 (94\%) experienced an improvement following surgery. Hyperprolactinemia improved remarkably in $29(94 \%)$ of 31 patients. In contrast, hypopituitarism resolved in only $16(55 \%)$ of 29 patients, and DI in 11 (65\%) of 17 patients. There was a significant difference in the rate of postoperative improvement in hypopituitarism among the RCC types; all but 1 patient in the intrasellar group improved (86\%), whereas only $29 \%$ of patients in the suprasellar group improved ( $\mathrm{p}$ $=0.02$ ). Hypocortisolism and hypogonadism resolved in $62 \%$ and $54 \%$ of patients, respectively. Growth hormone deficiency and hypothyroidism resolved in only $33 \%$ and $35 \%$ of patients, respectively. Eight patients $(9.2 \%)$ had new hypopituitarism, and 5 patients $(5.7 \%)$ had new DI after cyst evacuation/resection. New postoperative hypopituitarism was encountered in 1 patient with a suprasellar RCC, 2 with intrasellar RCC, and 5 with intrasuprasellar RCC. There was no significant difference in the occurrence of new postoperative hypopituitarism among the 3 types of RCC.

\section{Recurrence}

The mean time to recurrence was $14 \pm 6$ months Eleven patients (12.6\%) had MRI evidence of the reaccumulation of cyst fluid; 7 (63.6\%) of these 11 patients had symptomatic recurrence. All but 1 recurrent case demonstrated homogeneous isointensity on T2-weighted MRI. Two patients underwent a traditional craniotomy for cyst recurrence, and the other 5 patients underwent repeat endonasal surgery. The recurrent RCCs were treated based on the same principles as the primary cases. Aggressive complete resection of the cyst wall was attempted in all recurrent cases. No new deficits were noted in any pa- 
tient who underwent resection of a recurrent cyst. Four of the recurrent cysts (57\%) had a tumor-like appearance on preoperative MRI, and histopathology demonstrated squamous metaplasia (Fig. 4). Cyst recurrence was associated with a suprasellar cyst location $(\mathrm{p}=0.024)$, squamous metaplasia ( $\mathrm{p}<0.0001)$, and isointensity on T2-weighted MRI ( $p=0.006)$ on univariate analysis. Interestingly, cyst recurrence was not associated with the extent of resection. Logistic regression analysis demonstrated suprasellar cyst location ( $\mathrm{p}=0.007$, OR 7.7, 95\% CI 1.75-34.54), occurrence of squamous metaplasia $(\mathrm{p}=0.007$, OR $19.3,95 \%$ CI 2.25-165.18), and isointensity on T2-weighted MRI (p $=0.041$, OR $10.29,95 \%$ CI 1.094-96.872) as the independent predictors of RCC recurrence (Table 3 ).

Recurrence-free survival was $84.5 \%$ at a mean of 98.2 \pm 4.6 months after treatment (Fig. 5). The RFS for intrasellar, intrasuprasellar, and suprasellar RCCs was $100 \%$, $90 \%$ (105.33 \pm 4.3 months), and 71.4\% (78.1 \pm 11 months), respectively. The difference in RFS among the RCC types was significant (log-rank/Mantel-Cox, $\lambda^{2}=7.8, \mathrm{p}=0.005$ ). Recurrence-free survival for patients with squamous metaplasia was $60 \%$ (65.2 \pm 6.8 months). There was a significant difference in RFS among the RCC types with and without squamous metaplasia (log-rank/Mantel-Cox, $\lambda^{2}=$ 20.2 , $\mathrm{p}<0.0001)$. Recurrence-free survival for the intrasuprasellar cyst type with squamous metaplasia was $64.3 \%$, mean $74.3 \pm 7.8$ months, and that for the suprasellar cyst with squamous metaplasia was $54.5 \%$, mean $44.6 \pm 6.4$ months (log-rank/Mantel-Cox, $\lambda^{2}=24.9$, $\mathrm{p}<0.0001$ ).

\section{Discussion}

The rate of recurrence after surgical evacuation of an

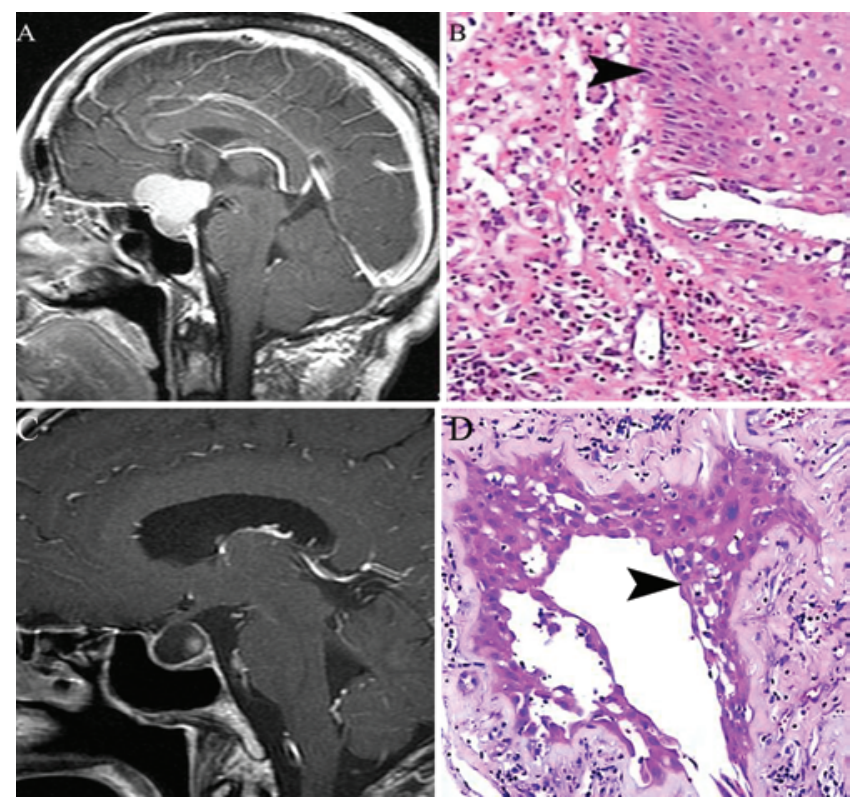

FIG. 4. Sagittal Gd-enhanced T1-weighted MR image (A) showing tumor-like appearance of a recurrent suprasellar RCC. Photomicrograph (B) of cyst wall showing squamous metaplasia (black arrowhead). Sagittal Gd-enhanced T1-weighted MR image (C) showing a recurrent cyst with peripheral rim enhancement. Photomicrograph (D) of cyst wall showing squamous metaplasia (black arrowhead). H \& E, original magnification $\times 25(B)$ and $\times 100$ (D). Figure is available in color online only.
TABLE 3. Multivariate logistic regression analysis for prediction of RCC recurrence

\begin{tabular}{lccc}
\hline \multicolumn{1}{c}{ Parameter } & OR & $95 \% \mathrm{Cl}$ & p Value \\
\hline Suprasellar RCC & 7.7 & $1.75-34.54$ & $0.007^{*}$ \\
\hline Isointensity on T2-weighted MRI & 10.29 & $1.094-96.872$ & $0.041^{*}$ \\
\hline Squamous metaplasia & 19.3 & $2.25-165.18$ & $0.007^{*}$ \\
\hline
\end{tabular}

* Statistically significant.

$\mathrm{RCC}$ has been reported to be in the range of $0 \%-42 \%$ at a mean follow-up of 5 years. ${ }^{1,13,18,26,31,33,38,39,45,51}$ Symptomatic recurrence has been reported in up to $57 \%$ of the patients with radiological evidence of recurrence. Table 4 features a summary of published studies on recurrence in surgically treated symptomatic RCCs. The rate of recurrence in the present study was $12.6 \%$ at a median of 5 years' follow-up. A suprasellar cyst location, squamous metaplasia, and isointensity on T2-weighted MRI were the independent predictors of cyst recurrence.

\section{Cyst Location}

A suprasellar cyst location was an independent predictor of squamous metaplasia and recurrence. The rate of recurrence increased by $17 \%$ (from $45.5 \%$ to $28.6 \%$ ) in suprasellar cysts with squamous metaplasia, as compared with those without squamous metaplasia. There was a significant association between a suprasellar RCC and a smaller cyst volume $\left(<2.5 \mathrm{~cm}^{3}, 10\right.$ [48\%] 21 cysts, $\mathrm{p}=$ $0.023)$. The suprasellar cyst causes compression of the optic chiasm and pituitary stalk and presents early with the compression symptoms. However, the intrasellar or intrasuprasellar type remains asymptomatic for a longer period of time, resulting in progressive growth and an increased mean cyst volume. Forty-two percent of intrasuprasellar RCCs had a cyst volume $>3.5 \mathrm{~cm}^{3}$. No recurrence was observed in the intrasellar type; $13 \%$ (2 of 16) of intrasellar RCCs had squamous metaplasia. The intrasuprasellar

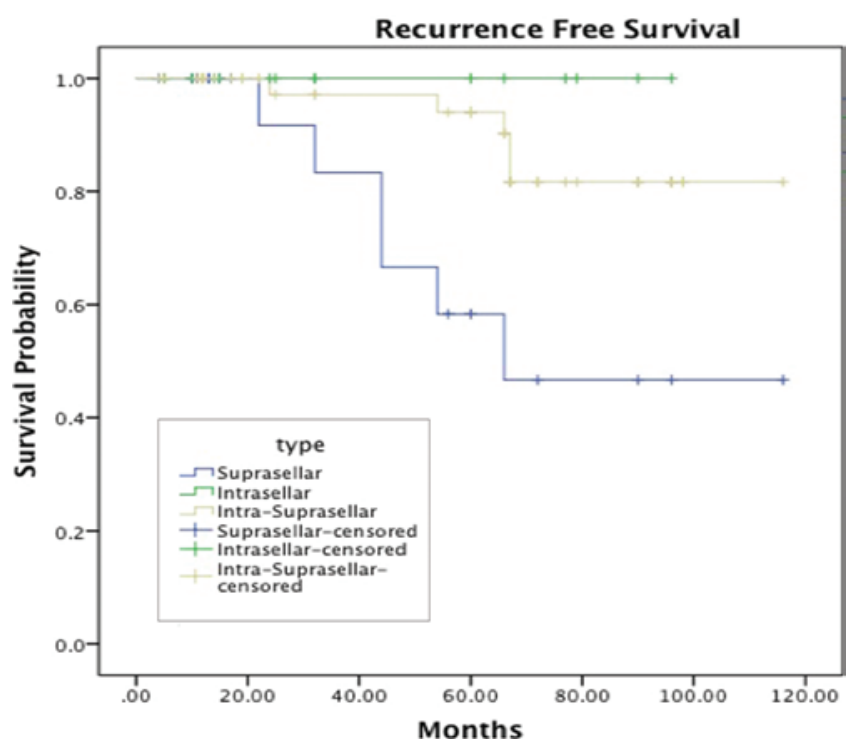

FIG. 5. Kaplan-Meier curve for RFS in patients with RCC. Figure is available in color online only. 


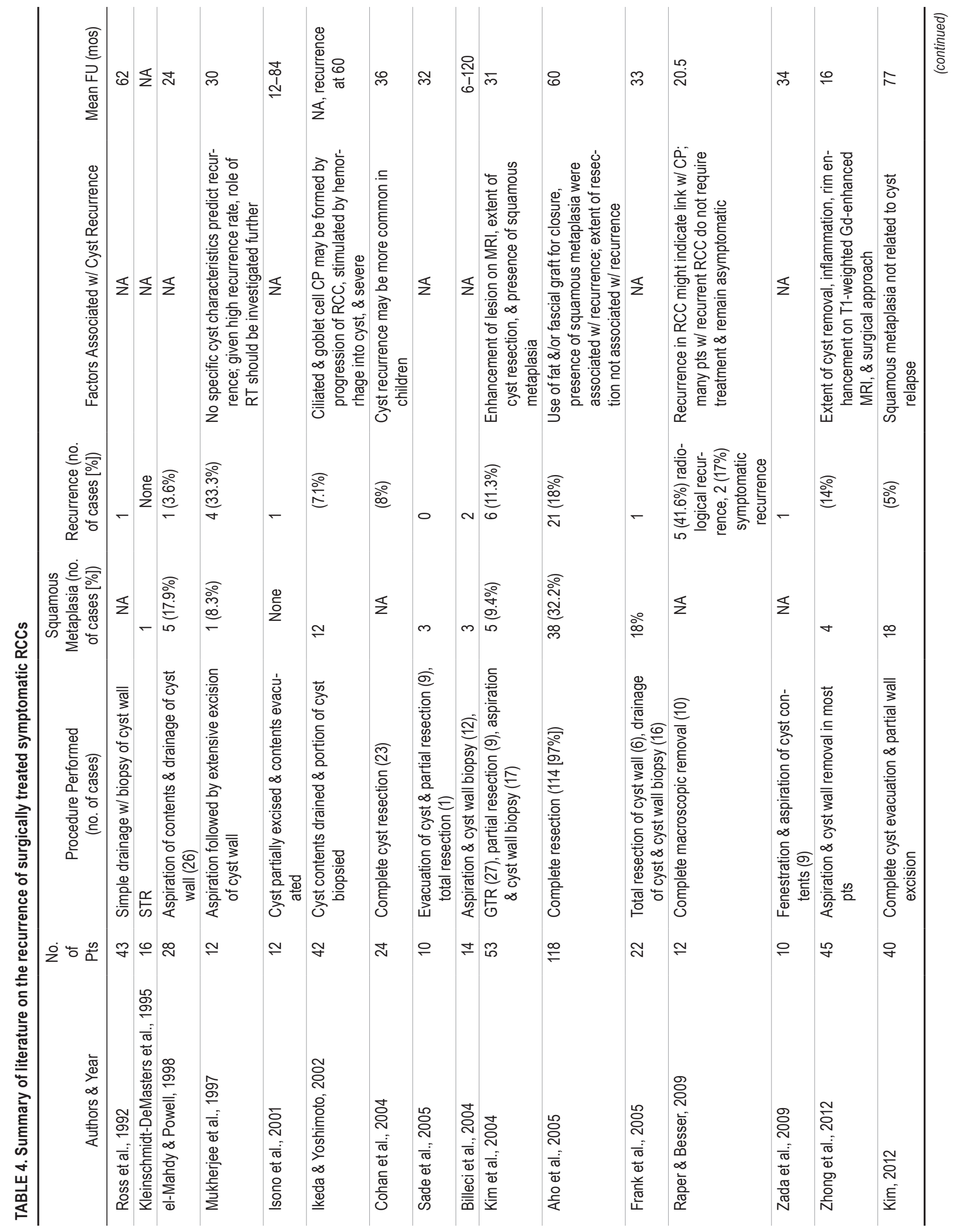


RCC was not associated with recurrence; $28 \%$ of patients with intrasuprasellar RCCs had squamous metaplasia.

\section{Squamous Metaplasia}

A suprasellar cyst location, ring enhancement on Gdenhanced MRI, hypointensity on T1-weighted MRI, and increased cyst volume were the independent predictors of squamous metaplasia. These preoperative parameters can be used to identify the occurrence of squamous metaplasia, which is an independent predictor of recurrence. Several theories have been proposed to account for the association between squamous metaplasia and recurrence. ${ }^{6,18,21,22,26,28,34,5153}$ One theory is that the RCC and craniopharyngioma are part of the same disease spectrum, and the transition from single cuboidal epithelium to squamous epithelium represents the type of RCCs that may be a close continuation of craniopharyngioma. The presence of squamous metaplasia makes the distinction between a papillary craniopharyngioma and an RCC difficult. . $8,27,31,33,35,40,52^{\text {In }}$ the present study, 4 of the 11 recurrent cases demonstrated a tumor-like appearance of the cyst on preoperative MRI; however, the histopathology revealed RCCs with squamous metaplasia (Fig. 4D). Similar findings in anecdotal cases have been reported in the literature. ${ }^{35,46}$ Papillary craniopharyngiomas are more solid, unlike RCCs, which demonstrate the presence of extensive ciliation with mucin production. Another theory for squamous metaplasia in RCC is that chronic inflammation may lead to metaplastic transformation from cuboidal and columnar to squamous epithelium. In a series of $151 \mathrm{RCCs}$, the authors reported no significant association between recurrence and squamous metaplasia or reactive inflammation..$^{39}$ In the present study, intraoperative inflammation was present in 13 (48\%) of 27 cases with squamous metaplasia. Inflammation in the cyst wall can appear as ring enhancement on preoperative MRI. We found that ring enhancement was present in $81 \%$ of the cases with squamous metaplasia and was an independent predictor of squamous metaplasia. An increased cyst volume predicted the occurrence of squamous metaplasia in the cyst wall. A large RCC may represent chronic growth of the cyst, which may predispose the cyst wall to inflammation and metaplastic transformation.

\section{Magnetic Resonance Imaging}

The variable signal intensity on preoperative MRI has been associated with the number and type of secretory cells, the presence or absence of chronic inflammation, and the rate of cell desquamation. ${ }^{50}$ As previously demonstrated, hypointensity on T1-weighted MRI and ring enhancement on Gd-enhanced T1-weighted MRI were independent predictors of squamous metaplasia. The peripheral rim enhancement has been attributed to changes due to squamous metaplasia, inflammation, a circumscribed area of pituitary tissue peripheral to the cyst wall, or deposition of hemosiderin or cholesterol crystals in the cyst wall. ${ }^{3}$ Most of the recurrent cases (10 of 11) demonstrated isointensity on T2-weighted MRI, which was an independent predictor of recurrence in our study.

\section{Cyst Resection}

Surgical treatment frequently provides relief of head- 
aches and visual disturbances, and sometimes even improves endocrine dysfunction. The surgical treatment of RCC has evolved with advances in techniques and a better understanding of the cyst's natural history. Traditionally, transcranial approaches were used with complete excision of the cyst and cyst wall fenestration. Radical resection of the cyst wall was performed in 15 of our early cases with the intention of reducing the recurrence rate..$^{10,26}$ Later on in our series, cyst evacuation, along with partial resection of the cyst wall that did not adhere to the pituitary gland, was performed. ${ }^{11,22,51}$ For recurrent RCCs, studies have recommended aggressive removal of cyst wall in the suprasellar cistern to allow communication between the cyst and CSF spaces followed by postoperative irradiation. ${ }^{33}$ None of the cases in the present study received postoperative radiation. Few authors have reported a significant association between the extent of cyst resection and recurrence. ${ }^{18,26}$ In present study, however, we observed no association between the extent of resection and recurrence. A higher incidence of postoperative hypopituitarism and CSF leakage is associated with the aggressive resection of predominantly intrasellar RCCs. ${ }^{41}$ Aggressive resection of the cyst wall may not be necessary in intrasellar RCCs given that there were no cases of recurrence in this group with and without squamous metaplasia. For purely suprasellar RCCs, aggressive resection of the cyst wall may be reasonable, as the suprasellar location was an independent predictor of squamous metaplasia and recurrence. In a review of the literature, a microsurgical transsphenoidal approach was found to have a higher rate of recurrence (14\% vs $8 \%$ ) and new endocrine dysfunction (25\% vs $10 \%)$ compared to the endoscopic approach. ${ }^{30}$ In the present study, the surgical approach used significantly differed among the different types of RCC; for example, suprasellar RCCs were resected via the transcranial pterional/subfrontal approach or supraorbital keyhole craniotomy. For most intrasuprasellar RCCs and for all intrasellar RCCs, an endonasal transsphenoidal approach was optimal. But for a few intrasuprasellar RCCs with a large volume $(>3$ $\mathrm{cm}^{3}$ ) or for those with primary suprasellar extension, the transcranial approach allowed better resection without transgression of the pituitary. The extent of resection and recurrence were not associated with the type of surgical approach performed.

\section{Study Limitations}

Despite the contributions that this study makes to the literature, it has several notable limitations. It is a singlecenter experience, and thus bears all the limitations associated with a retrospective study design. The number of patients in each RCC type is relatively small. Additional studies with a multicenter prospective design and a larger number of patients with each RCC type may provide more robust data for an analysis of predictors of squamous metaplasia and recurrence.

\section{Conclusions}

A suprasellar cyst location, ring enhancement on Gdenhanced MRI, hypointensity on T1-weighted MRI, and cyst volume were the independent predictors of squamous metaplasia. A suprasellar cyst location, the occurrence of squamous metaplasia, and isointensity on T2-weighted MRI were the independent predictors of RCC recurrence. The extent of resection and type of surgical approach used was not associated with recurrence. Aggressive resection may be reasonable in recurrent cases. A tailored extent of resection based on cyst location and predictive factors is recommended.

\section{Acknowledgments}

We thank Dr. Deng Yongjian for assistance with pathological evaluation, and we appreciate Jun Fan, MD, Yuping Peng, MD, and Binghui Qiu, MD, for their involvement in the care of the patients and for providing the data on the patients included in this study.

\section{References}

1. Aho CJ, Liu C, Zelman V, Couldwell WT, Weiss MH: Surgical outcomes in 118 patients with Rathke cleft cysts. J Neurosurg 102:189-193, 2005

2. Amhaz HH, Chamoun RB, Waguespack SG, Shah K, McCutcheon IE: Spontaneous involution of Rathke cleft cysts: is it rare or just underreported? J Neurosurg 112:1327-1332, 2010

3. Asari S, Ito T, Tsuchida S, Tsutsui T: MR appearance and cyst content of Rathke cleft cysts. J Comput Assist Tomogr 14:532-535, 1990

4. Barrow DL, Spector RH, Takei Y, Tindall GT: Symptomatic Rathke's cleft cysts located entirely in the suprasellar region: review of diagnosis, management, and pathogenesis. Neurosurgery 16:766-772, 1985

5. Baskin DS, Wilson CB: Transsphenoidal treatment of nonneoplastic intrasellar cysts. A report of 38 cases. J Neurosurg 60:8-13, 1984

6. Billeci D, Marton E, Tripodi M, Orvieto E, Longatti P: Symptomatic Rathke's cleft cysts: a radiological, surgical and pathological review. Pituitary 7:131-137, 2004

7. Binning MJ, Liu JK, Gannon J, Osborn AG, Couldwell WT: Hemorrhagic and nonhemorrhagic Rathke cleft cysts mimicking pituitary apoplexy. J Neurosurg 108:3-8, 2008

8. Brassier G, Morandi X, Tayiar E, Riffaud L, Chabert E, Heresbach N, et al: Rathke's cleft cysts: surgical-MRI correlation in 16 symptomatic cases. J Neuroradiol 26:162-171, 1999

9. Cohan P, Foulad A, Esposito F, Martin NA, Kelly DF: Symptomatic Rathke's cleft cysts: a report of 24 cases. J Endocrinol Invest 27:943-948, 2004

10. Eisenberg HM, Sarwar M, Schochet S Jr: Symptomatic Rathke's cleft cyst. Case report. J Neurosurg 45:585-588, 1976

11. el-Mahdy W, Powell M: Transsphenoidal management of 28 symptomatic Rathke's cleft cysts, with special reference to visual and hormonal recovery. Neurosurgery 42:7-17, 1998

12. Fager CA, Carter H: Intrasellar epithelial cysts. J Neurosurg 24:77-81, 1966

13. Fan J, Peng Y, Qi S, Zhang XA, Qiu B, Pan J: Individualized surgical strategies for Rathke cleft cyst based on cyst location. J Neurosurg 119:1437-1446, 2013

14. Fan MC, Wang QL, Wang JF, Deng WS, Li LD, Wang ZH, et al: Surgical treatment of symptomatic Rathke's cleft cysts: clinical features, therapy considerations and outcomes. Chin Med J (Engl) 125:2919-2924, 2012

15. Frank G, Sciarretta V, Mazzatenta D, Farneti G, Modugno GC, Pasquini E: Transsphenoidal endoscopic approach in the treatment of Rathke's cleft cyst. Neurosurgery 56:124-129, 2005

16. Frazier CH, Alpers BJ: Tumors of Rathke's cleft (hitherto called tumors of Rathke's pouch). Arch Neurol Psychiatry 32:973-984, 1934 
17. Goldzieher M: Über Sektionsbefunde Bei Diabetes Insipidus. Verh Dtsch Ges Pathol 16:281-287, 1913

18. Han SJ, Rolston JD, Jahangiri A, Aghi MK: Rathke's cleft cysts: review of natural history and surgical outcomes. J Neurooncol 117:197-203, 2014

19. Harrison MJ, Morgello S, Post KD: Epithelial cystic lesions of the sellar and parasellar region: a continuum of ectodermal derivatives? J Neurosurg 80:1018-1025, 1994

20. Higgins DM, Van Gompel JJ, Nippoldt TB, Meyer FB: Symptomatic Rathke cleft cysts: extent of resection and surgical complications. Neurosurg Focus 31(1):E2, 2011

21. Hofmann BM, Kreutzer J, Saeger W, Buchfelder M, Blümcke I, Fahlbusch R, et al: Nuclear beta-catenin accumulation as reliable marker for the differentiation between cystic craniopharyngiomas and rathke cleft cysts: a clinico-pathologic approach. Am J Surg Pathol 30:1595-1603, 2006

22. Ikeda H, Yoshimoto T: Clinicopathological study of Rathke's cleft cysts. Clin Neuropathol 21:82-91, 2002

23. Ikeda H, Yoshimoto T, Suzuki J: Immunohistochemical study of Rathke's cleft cyst. Acta Neuropathol 77:33-38, 1988

24. Isono M, Kamida T, Kobayashi H, Shimomura T, Matsuyama J: Clinical features of symptomatic Rathke's cleft cyst. Clin Neurol Neurosurg 103:96-100, 2001

25. Kim E: Symptomatic Rathke cleft cyst: clinical features and surgical outcomes. World Neurosurg 78:527-534, 2012

26. Kim JE, Kim JH, Kim OL, Paek SH, Kim DG, Chi JG, et al: Surgical treatment of symptomatic Rathke cleft cysts: clinical features and results with special attention to recurrence. J Neurosurg 100:33-40, 2004

27. Kleinschmidt-DeMasters BK, Lillehei KO, Stears JC: The pathologic, surgical, and MR spectrum of Rathke cleft cysts. Surg Neurol 44:19-27, 1995

28. Komatsu F, Tsugu H, Komatsu M, Sakamoto S, Oshiro S, Fukushima T, et al: Clinicopathological characteristics in patients presenting with acute onset of symptoms caused by Rathke's cleft cysts. Acta Neurochir (Wien) 152:1673-1678, 2010

29. Lillehei KO, Widdel L, Astete CA, Wierman ME, Kleinschmidt-DeMasters BK, Kerr JM: Transsphenoidal resection of 82 Rathke cleft cysts: limited value of alcohol cauterization in reducing recurrence rates. J Neurosurg 114:310-317, 2011

30. Mendelson ZS, Husain Q, Elmoursi S, Svider PF, Eloy JA, Liu JK: Rathke's cleft cyst recurrence after transsphenoidal surgery: a meta-analysis of 1151 cases. J Clin Neurosci 21:378-385, 2014

31. Mukherjee JJ, Islam N, Kaltsas G, Lowe DG, Charlesworth M, Afshar F, et al: Clinical, radiological and pathological features of patients with Rathke's cleft cysts: tumors that may recur. J Clin Endocrinol Metab 82:2357-2362, 1997

32. Munich SA, Leonardo J: Spontaneous involution of a Rathke's cleft cyst in a patient with normal cortisol secretion. Surg Neurol Int 3:42, 2012

33. Ogawa Y, Watanabe M, Tominaga T: Prognostic factors of operated Rathke's cleft cysts with special reference to reaccumulation and recommended surgical strategy. Acta Neurochir (Wien) 153:2427-2433, 2011

34. Ogawa Y, Watanabe M, Tominaga T: Rathke's cleft cysts with significant squamous metaplasia-high risk of postoperative deterioration and close origins to craniopharyngioma. Acta Neurochir (Wien) 155:1069-1075, 2013

35. Oka H, Kawano N, Yagishita S, Suwa T, Yoshida T, Maezawa $\mathrm{H}$, et al: Origin of ciliated craniopharyngioma: pathological relationship between Rathke cleft cyst and ciliated craniopharyngioma. Noshuyo Byori 12:97-103, 1995

36. Park JK, Lee EJ, Kim SH: Optimal surgical approaches for Rathke cleft cyst with consideration of endocrine function. Neurosurgery 70 (2 Suppl Operative):250-257, 2012

37. Pawar SJ, Sharma RR, Lad SD, Dev E, Devadas RV: Rathke's cleft cyst presenting as pituitary apoplexy. J Clin Neurosci 9:76-79, 2002
38. Post KD: Rathke's cleft cysts: unanswered questions. World Neurosurg 78:428-429, 2012

39. Potts MB, Jahangiri A, Lamborn KR, Blevins LS, Kunwar S, Aghi MK: Suprasellar Rathke cleft cysts: clinical presentation and treatment outcomes. Neurosurgery 69:1058-1068, 2011

40. Qi ST, Zhou J, Pan J, Zhang C, Silky C, Yan XR: Epithelialmesenchymal transition and clinicopathological correlation in craniopharyngioma. Histopathology 61:711-725, 2012

41. Raper DM, Besser M: Clinical features, management and recurrence of symptomatic Rathke's cleft cyst. J Clin Neurosci 16:385-389, 2009

42. Rosales MY, Smith TW, Safran M: Hemorrhagic Rathke's cleft cyst presenting as diplopia. Endocr Pract 10:129-134, 2004

43. Ross DA, Norman D, Wilson CB: Radiologic characteristics and results of surgical management of Rathke's cysts in 43 patients. Neurosurgery 30:173-179, 1992

44. Rottenberg GT, Chong WK, Powell M, Kendall BE: Cyst formation of the craniopharyngeal duct. Clin Radiol 49:126129, 1994

45. Sade B, Albrecht S, Assimakopoulos P, Vézina JL, Mohr G: Management of Rathke's cleft cysts. Surg Neurol 63:459466,2005

46. Sato K, Oka H, Utsuki S, Kondo K, Kurata A, Fujii K: Ciliated craniopharyngioma may arise from Rathke cleft cyst. Clin Neuropathol 25:25-28, 2006

47. Shanklin WM: On the presence of cysts in the human pituitary. Anat Rec 104:379-407, 1949

48. Shin JL, Asa SL, Woodhouse LJ, Smyth HS, Ezzat S: Cystic lesions of the pituitary: clinicopathological features distinguishing craniopharyngioma, Rathke's cleft cyst, and arachnoid cyst. J Clin Endocrinol Metab 84:3972-3982, 1999

49. Steinberg GK, Koenig GH, Golden JB: Symptomatic Rathke's cleft cysts. Report of two cases. J Neurosurg 56:290-295, 1982

50. Trifanescu R, Ansorge O, Wass JA, Grossman AB, Karavitaki N: Rathke's cleft cysts. Clin Endocrinol (Oxf) 76:151160,2012

51. Voelker JL, Campbell RL, Muller J: Clinical, radiographic, and pathological features of symptomatic Rathke's cleft cysts. J Neurosurg 74:535-544, 1991

52. Wolfe SQ, Heros RC: Editorial. A Rathke cleft cyst to craniopharyngioma: is there a spectrum? J Neurosurg 112:13221323,2010

53. Xin W, Rubin MA, McKeever PE: Differential expression of cytokeratins 8 and 20 distinguishes craniopharyngioma from Rathke cleft cyst. Arch Pathol Lab Med 126:1174-1178, 2002

54. Zada G: Rathke cleft cysts: a review of clinical and surgical management. Neurosurg Focus 31(1):E1, 2011

55. Zada G, Ditty B, McNatt SA, McComb JG, Krieger MD: Surgical treatment of rathke cleft cysts in children. Neurosurgery 64:1132-1038, 2009

56. Zhong W, You C, Jiang S, Huang S, Chen H, Liu J, et al: Symptomatic Rathke cleft cyst. J Clin Neurosci 19:501-508, 2012

\section{Author Contributions}

Conception and design: Chotai, Liu, Pan. Acquisition of data: Liu. Analysis and interpretation of data: Chotai, Liu. Drafting the article: Chotai. Critically revising the article: Chotai, Liu, Qi. Reviewed submitted version of manuscript: Chotai, Qi, Liu, Pan. Approved the final version of the manuscript on behalf of all authors: Chotai. Statistical analysis: Chotai, Liu. Administrative/ technical/material support: Pan. Study supervision: Pan, Qi.

\section{Correspondence}

Songtao Qi, Department of Neurosurgery, Nanfang Hospital, Southern Medical University, Guangzhou 510515, China. email: silky.chotai@live.com. 